\title{
Práticas de interação e seus processos de aprendizagem coletivos em uma cooperativa popular
}

\author{
Interaction practices and their collective learning processes in a popular cooperative
}

Selma Aguiar Jagher ${ }^{[a]}$, Yára Lúcia Mazziotti Bulgacovib]

\footnotetext{
${ }^{[a]}$ Mestre em Administração pela Universidade Positivo (UP), Curitiba, PR - Brasil, e-mail: selma.jagher@gmail.com

${ }^{[b]}$ Doutora em Educação, professora da Universidade Positivo (UP), Curitiba, PR - Brasil, e-mail: ybulgacov@gmail.com
}

Recebido: 22/03/2012 Received: 03/22/2012

Aprovado: $18 / 11 / 2012$ Approved: 11/18/2012

\section{Resumo}

A aprendizagem tem sido alvo de discussões frequentes nos meios acadêmicos. Assim, este artigo tem por objetivo analisar práticas sociais coletivas e suas possibilidades de aprendizagem expansiva sob a perspectiva da Teoria da Atividade Histórico-Cultural (Engeström, 2001). Teve-se como pressuposto que o ambiente cooperativo, dada algumas condições, possibilita a aprendizagem coletiva levando os indivíduos a construírem uma nova realidade. Na busca de compreensão desse fenômeno, desenvolveu-se uma pesquisa qualitativa, de natureza exploratória. Partiu-se de uma revisão bibliográfica e documental utilizando como técnicas de coleta de dados de observação e entrevista em profundidade. Para analisar o caso empírico utilizou-se a história oral. Os resultados permitiram reconhecer a importância das relações sociais da cooperativa, da historicidade, da existência de multivozes, das (con)tradições, bem como das mediações culturais. Percebeu-se que os cooperados são capazes de expandir os ensinamentos recebidos pela incubadora, adaptando esses ensinamentos a suas realidades e desenvolvendo novas práticas. Constatou-se, entretanto, que essas novas práticas não foram suficientes para a conquista da autonomia da cooperativa.

Palavras-chaves: Teoria da atividade. Aprendizagem expansiva. Cooperativa popular.

\begin{abstract}
Learning has been the subject of frequent debate in the academic environments. Therefore, the aim of this article is to analyze collective social practices and their potential for expansive learning in the perspective of the Cultural Historical Activity Theory (Engeström, 2001). The assumption was that the cooperative environment, given certain conditions, enables collective learning, leading individuals to construct a new reality. When seeking to understand this phenomenon, a qualitative study of an exploratory nature was conducted, beginning with a bibliographic and documental review, with observation and in-depth interviews as the data collection techniques. To analyze the empirical case, oral history was used. The results made it possible to recognize the importance of the social relations of the cooperative, its historicity and the existence of multiple voices with traditions, in addition to cultural mediation within the cooperative. It was noted that those involved in cooperation are capable of expanding on the teaching they receive through
\end{abstract}

Psicol. Argum. 2014 jul./set., 32(78), 27-38 
incubation, adapting it to their own reality and developing new practices. However, these practices were found to be insufficient for achieving the autonomy of the cooperative.

Keywords: Theory of activity. Expansive learning process. Popular cooperative.

\section{Introdução}

As desigualdades que assolam o Brasil são um problema antigo e, apesar das recentes conquistas apontadas pelos indicadores do Governo Federal, essas não foram suficientes para que nos tornássemos um país que oferece condições mínimas de igualdade a sua população. Indicadores sociais (moradia, emprego, renda, saúde, segurança e educação) mostram que existem situações de desigualdades que precisam ser vencidas, e seu enfrentamento requer, entre outras coisas, a criação de oportunidades de emprego e de geração de renda, melhorando assim a qualidade de vida de sua população.

Múltiplas iniciativas governamentais ou não governamentais são geradas nas mais diversas áreas sociais com o objetivo de combater essas desigualdades, sendo que uma delas é a Incubadora Tecnológica de Cooperativas Populares da Universidade Federal do Paraná (ITCP-UFPR).

Partindo dessa realidade, este artigo se propôs a estudar uma cooperativa de pequenos agricultores e artesãos, fundada em 1999, e que se mantém em atividade em Curitiba-PR, incubada por esse programa.

Teve-se como objetivo identificar as práticas coletivas de interação dos cooperados, com vistas a identificar as condições de aprendizagem expansiva. Assim, buscou-se responder: como se dá, a partir das práticas coletivas de interação, o processo de aprendizagem expansiva em uma cooperativa popular incubada pela ITCP-UFPR?

Partiu-se do pressuposto de que a aprendizagem é algo esperado em sistema cooperativo, dadas algumas condições da interação, e que as pessoas não apenas aprendem, mas ampliam sua aprendizagem, podendo tornar-se autônomas, inclusive conduzindo a práticas de sustentabilidade, autonomia e melhor qualidade de vida.

Desta forma, este estudo foi conduzido de forma a identificar as práticas coletivas de interação dos cooperados a partir da ação da incubadora. Pretendeu-se, ainda, identificar se houve expansão da aprendizagem coletiva, atendendo aos princípios teóricos do ciclo de aprendizagem expansivo de Engeström (2001).

Como estrutura deste artigo, após a apresentação dos fundamentos teóricos da pesquisa, segue-se a metodologia, a análise e a discussão dos dados e as considerações finais.

\section{Fundamentos teóricos}

A parte teórica trata dos conceitos de economia solidária e de cooperativismo popular, seguida de uma apresentação dos princípios da Teoria da Atividade e do Ciclo Expansivo da Aprendizagem.

\section{A economia solidária e o cooperativismo popular}

A economia social é um termo utilizado pela União Europeia, particularmente pela Europa continental, caracterizado por um forte envolvimento pessoal de seus membros na gestão da empresa e a ausência da procura de lucros, a fim de remunerar o capital dos acionistas. Organizações com modelo específico de funcionamento democrático e de solidariedade entre os membros, em que se privilegia a geração de empregos, coesão social, desenvolvimento regional e rural, proteção ambiental, defesa do consumidor, segurança e políticas sociais. No entanto, essas organizações precisam competir no mercado como qualquer outro negócio, buscando o sucesso comercial para que possam utilizar seus lucros para apoiar sua finalidade social.

Segundo Neamtan (2002), em documento publicado pela UNESCO, o termo economia social combina dois termos que são muitas vezes contraditórios, nos quais "economia" se refere à produção de bens concretos ou à prestação de serviços através de negócios ou empreendimentos que contribuem para um aumento líquido da riqueza, e "social" refere-se à rentabilidade social, em oposição ao conceito de aferição pura do lucro; nesse a rentabilidade social contribui para a melhoria da qualidade de vida, e do bem-estar da população, nomeadamente 
através do aumento das disponibilidades de serviços (Neamtan, 2002, p. 1).

As empresas da economia social estão presentes em quase todos os setores da economia, tais como bancos, seguros, agricultura, artesanato, diversos serviços comerciais, serviços sociais, de saúde, etc., sendo na sua maioria pequenas e médias empresas (PME), que, comercializando seus produtos ou serviços, geram receitas por meio de suas atividades econômicas. Assim, o termo economia social atende, do ponto de vista jurídico, ao universo constituído por quatro tipos organizacionais fundamentais: as cooperativas, as organizações mutualistas, as fundações e algumas formas de associação de grande porte.

Para França Filho (2002, p. 12), "a economia solidária e a economia social remetem a dois universos distintos de experiências, sendo que as características assumidas pela economia social vêm demarcar a noção de economia solidária". Esse autor ainda destaca que os fenômenos da economia social e solidária remetem às características de hibridação de economias, possibilitando uma combinação de economia mercantil, não mercantil e não monetária. Isso porque, nessas iniciativas de economia solidária, essas economias coexistem: venda de um produto ou prestação de um serviço (recurso mercantil); subsídios públicos oriundos do reconhecimento da natureza de utilidade social da ação organizacional (recurso não mercantil); e trabalho voluntário (recurso não monetário).

Andion (2005) entende economia solidária como organizações criadas a partir de uma mobilização da sociedade civil na qual predominam formas de regulação baseadas na reciprocidade, tais como o dom e o voluntariado que, por sua vez, são indissociáveis das relações pessoais presentes na esfera comunitária.

Apesar de não haver consenso sobre os conceitos de Economia Solidária e suas implicações para a economia no país, a Secretaria Nacional de Economia Solidária do Ministério do Trabalho e Emprego (SENAES/MTE) procurou estabelecer esse consenso, pelo menos no que diz respeito ao entendimento dado pelo Governo Federal, conceituando no âmbito do SIES:

Economia Solidária é compreendida como o conjunto de atividades econômicas - de produção, distribuição, consumo, poupança e crédito - orga- nizados e realizados (sic) solidariamente por trabalhadores e trabalhadoras sob a forma coletiva e autogestionária (SENAES, 2006).

Alinhado com esses pressupostos, Singer (2002, 2005) define Economia Solidária como sendo outro modelo que privilegia a propriedade coletiva ou associada do capital e o direito à liberdade individual, em que o resultado natural é a solidariedade e a igualdade, sem perder de vista que ela precisa ser organizada igualitariamente pelos que se associam para produzir, comerciar, consumir ou poupar.

\section{A teoria da atividade}

A Teoria da Atividade Histórico-Cultural (TA) tem como principal desafio explicar como as relações entre os indivíduos, seu ambiente e as ferramentas que utilizam em seu cotidiano com foco nas mudanças qualitativas nas práticas humanas.

Essa abordagem tem como conceito central a mediação; esse conceito teve Vygotsky como precursor, que rompeu a concepção linear e determinista de ambiente-comportamento, bem como o conceito de "internalização" enquanto relação linear e determinística de ambiente. 0 homem age sobre o mundo e sua ação é resultado de complexas relações historicamente acumuladas e transmitidas bem como de sua história singular. A teoria teve contribuições significativas de Leontiev (1981), que enfatizou o desenvolvimento da atividade coletiva conjunta com outras pessoas, a importância da relação com outras pessoas, um processo mediado por ferramentas e ao mesmo tempo mediado socialmente.

Na evolução da TA proposta por Vygotsky (1978) e seus seguidores, encontramos Engeström (1999) que enfatizou o coletivo em estruturas de cooperação. Argumentou que as metas são reformuladas e revisadas à medida que as pessoas agem no coletivo em estruturas de cooperação e, em geral, propiciando a construção e a redefinição do objeto que está relacionado ao potencial criativo da atividade.

\section{0 ciclo expansivo}

Engeström (1987) é o precursor do ciclo expansivo na teoria da Atividade. Introduziu o conceito de aprendizagem expansiva o que implica a expansão do objeto, que, ao considerar o motivo do que

Psicol. Argum. 2014 jul./set., 32(78), 27-38 
é produzido e por que são formulados e reformulados, frequentemente levam à formação de novas relações entre o motivo e a atividade.

O ciclo expansivo se configura a partir do desenvolvimento de contradições e tensões entre os indivíduos e suas influências socioculturais entre dois ou mais elementos do sistema de atividade e/ou entre diferentes sistemas, uma vez que consideramos a aprendizagem como "um ciclo nunca acabado, um ciclo espiral de apropriação, transformação em contradições e expansão em novas atividades de aprendizagem" (Engeström, 1987). Para esse autor, a TA contempla aspectos sociais pertinentes à realização da atividade, a saber: as regras, a comunidade e a divisão do trabalho. 0 modelo básico da aprendizagem expansiva é um ciclo ou uma espiral, na qual o ciclo expansivo começa com o questionamento individual sobre uma prática aceita, e ele gradualmente expande em um movimento para as ações coletivas, permitindo assim que novas formas de organização social surjam a partir de outra previamente existente. Essa prática de abstração é passo a passo enriquecida e transformada em um sistema concreto de manifestações múltiplas, constantemente em desenvolvimento.

Essas mudanças acontecem por meio de dois processos contínuos e interdependentes no desenvolvimento das atividades humanas, nas quais a internalização se caracteriza pela reprodução e transmissão do conhecimento e da cultura internalizada através de conhecimentos, conceitos, valores e significados, aplicando-os em suas relações sociais e sua externalização, que está ligada à capacidade criativa do ser humano, com a qual é possível transformar a realidade em que se vive, e está ligada com a capacidade criativa do indivíduo, superando o processo de reprodução/transmissão (internalização) e permitindo o surgimento de novas formas de organização social a partir desta transformação (Leontiev, 1974).

Para Engeström (2001), o conceito de aprendizagem expansiva melhor se visualiza a partir quatro questões: Quem aprende? Por que aprendem? 0 que aprendem? Como aprendem? Ao mesmo tempo é orientada para cinco princípios (Engeström, 1993, 1995, 1999), que norteiam todas as relações do homem com as atividades. Engeström descreve esses princípios:

Esse autor ainda afirma que um ciclo expansivo inicia quando os atores da atividade questionam uma prática aceita, que se expande gradualmente, dando origem a uma nova prática. Para Engeström (1999, p. 383), o aprendizado expansivo ocorre a partir de uma sequência que cria um ciclo expansivo que, em movimentos em espiral, é composta por sete etapas que se iniciam com os sujeitos questionando uma prática existente e se expande gradualmente em movimentos coletivos.

Em consequência deste questionamento, analisa-se a situação histórica e empírica para buscar as causas das contradições que geraram os questionamentos. Em outro momento, uma nova prática é modelada, vindo oferecer soluções para a situação-problema gerada pelo questionamento inicial. Os próximos passos são implantar a nova prática construída, refletir acerca dos resultados alcançados e consolidar essa nova prática.

0 autor ainda considera que em toda atividade social há conflito que gera instabilidade e contradição que, por sua vez, geram conflitos e perturbações essenciais que motivam as ações individuais e que são forças geradoras de mudanças e desenvolvimento. Essa instabilidade, por sua vez, faz parte da evolução e é o fator gerador de mudanças e de desenvolvimentos que não ocorrem só com o sujeito, mas também com o ambiente.

\begin{tabular}{|l|c|}
\hline $\begin{array}{l}\text { Sistema de atividade como } \\
\text { unidade de análise }\end{array}$ & $\begin{array}{c}\text { O objetivo individual ou do grupo é relativamente independente, porém subordinado a um } \\
\text { sistema de atividade. }\end{array}$ \\
\hline Voicedness ou múltiplas vozes & A comunidade com seus pontos de vista múltiplos, tradições e interesses. \\
\hline Historicidade & Os sistemas de atividade formam-se e são transformados ao longo do tempo. \\
\hline $\begin{array}{l}\text { Contradições como fontes de } \\
\text { mudança }\end{array}$ & $\begin{array}{c}\text { O acúmulo de tensões estruturais dentro e entre sistemas de atividade, mas também são } \\
\text { as contradições que promovem esforços de inovação e soluções adaptativas que provocam } \\
\text { mudança/desenvolvimento no sistema de atividade. }\end{array}$ \\
\hline $\begin{array}{l}\text { Transformações expansivas em } \\
\text { sistemas de atividade }\end{array}$ & $\begin{array}{c}\text { Acontece quando o objeto e o motivo da atividade são reconceituados para se adaptar a uma } \\
\text { nova atividade. }\end{array}$ \\
\hline
\end{tabular}

Figura 1 - Princípios de um Sistema de Atividade. Fonte: Adaptado de Engeström, 2001, pp. 137-139. 
Na proposição desse autor, os ciclos expansivos têm início com os indivíduos, com o questionamento às práticas aceitas em sua comunidade e com sua expansão gradual em um movimento coletivo. Porém, a formulação de novas propostas carece de discussões críticas, de rejeições e de reformulações para que sejam implementadas. Esse processo de reflexão é perpassado também pela negação, por destruições, por resistência, por confronto de culturas que se encontram, se chocam e não se reconhecem, gerando uma transformação coletiva.

Assim, para Engeström (1987), a aprendizagem emerge através de transformações que acontecem no sistema de atividade, sendo que esse processo ocorre inicialmente de forma individual e transpassa para o coletivo com a criação de novos instrumentos por meio de artefatos de mediação, signos e ferramentas, que são usados em conjunto pela comunidade para produzir um novo objeto e motivação no trabalho. Esse mesmo autor considera ainda que a aprendizagem não é apenas uma formação de rotinas coletivas, mas também a criação e implementação de novas ferramentas que são capazes de ampliar as rotinas existentes, tornando-se expansiva e assumindo o papel de renegociação das relações de colaboração e prática.

Para Engeström (1987), o processo de aprendizagem é e pode ser pensado como um ciclo expansivo, sendo que, por meio de questionamentos dos indivíduos acerca de práticas socialmente aceitas elas são repensadas, ressignificadas e recriadas.

0 ciclo de aprendizagem se caracteriza por sete etapas distintas, classificadas por Engeström (1999) da seguinte forma: questionar, analisar, modelar uma solução, examinar o modelo, implementar o novo modelo, refletir sobre o processo e consolidar uma nova prática, em tese, em um processo contínuo.

\section{Metodologia}

Assim, com o objetivo de analisar, sob a perspectiva da teoria da atividade e a partir de práticas coletivas de interação, o processo de aprendizagem em uma cooperativa popular incubada pela ITCPUFPR, no Paraná, sob a ótica dos cooperados envolvidos no processo, optou-se por realizar um estudo de caso descritivo-exploratório, com abordagem qualitativa e interpretação de narrativa colhida por meio de história oral em entrevistas em profundidade a partir de roteiro semiestruturado.

Optou-se pelo estudo de caso por buscar questões explicativas e que acontecem ao longo do tempo, no qual o pesquisador tem pouco controle sobre os eventos. A pesquisa envolveu 8 pessoas, sendo 2 dirigentes e 6 membros da cooperativa, tendo seus dados coletados a partir de entrevistas, análise documental e observações diretas.

As entrevistas foram conduzidas de forma a resgatar as experiências vividas pelos atores que o compõem, possuindo um caráter retrospectivo, considerando a possibilidade de solicitar aos participantes uma reflexão sobre suas experiências e atitudes, levando em conta em sua narrativa os dados de sua trajetória.

Utilizamos a história porque permite explorar as mudanças ocorridas ao longo do tempo de vida dos atores envolvidos no estudo, utilizando o questionamento retrospectivo de fatos ocorridos ao longo do tempo que foi previamente estabelecido, levando esses atores a considerar as múltiplas experiências em sua vida, em vez de se concentrar em um único episódio ou experiência.

\section{Discussão e análise dos dados}

A Cooperativa de Produtores Rurais e Artesãos iniciou suas atividades em 1999 a partir da iniciativa da Prefeitura local que, com a ITPC-UFPR, passou a reunir família carentes e pequenos produtores rurais em cursos de cooperativismo e associativismo, tendo como objetivo ajudar os produtores rurais e artesãos a venderem sua produção, oportunizando renda a essas famílias. Os primeiros cooperados foram organizados no número de 30 participantes, sendo todos trabalhadores autônomos (artesãos e pequenos agricultores) representados por $70 \%$ de mulheres e $30 \%$ de homens, a maioria com ensino fundamental incompleto, segundo dados da Próreitora de Extensão e Cultura da UFPR.

Os primeiros cooperados produziam basicamente produtos voltados à agricultura familiar, como verduras, hortaliças, feijão, cogumelo do sol e, ain$\mathrm{da}$, artesanato em geral como carrinhos de madeira, bonecas de tecido, bordados, enfim, uma grande quantidade de produtos que até então era comercializada de forma desarticulada.

Desde a criação da cooperativa, a figura do ITCP-UFPR foi o principal agente integrador da

Psicol. Argum. 2014 jul./set., 32(78), 27-38 
comunidade, municiando os interessados com cursos de formação em cooperativismo e de acordo com Dozsa (2010), Coordenador da ITCP-UFPR, pôde-se observar que os cooperados se apropriaram das propostas da incubadora, materializado no sentimento de pertencimento da cooperativa, no reconhecimento dos mecanismos de produção e de gestão, e do papel solidário da cooperativa enquanto geradora de trabalho e renda. Atualmente a cooperativa é composta por 15 associados, sendo que grande parte são mulheres.

Para esclarecer a categoria de análise definida neste estudo como Práticas Coletivas de interação utilizamos o conceito de sistema de atividade da Teoria da Atividade (Engeström, 1999). 0 sistema de atividade foi compreendido a partir dos cooperados individuais, atores da atividade; da atividade de cooperado como objeto; da comunidade como o grupo de cooperados que compartilha os mesmos objetos; dos artefatos, ferramentas ou signos mediando a atividade e direcionando esforços na busca dos resultados almejados; da divisão de trabalho se refere à divisão horizontal e vertical de tarefas entre os membros da cooperativa; e, finalmente, das regras, normas ou regulamentos explícitos e implícitos que restringem as ações e interações dentro do sistema de atividade da cooperativa.

Foram mapeadas as ações e tarefas desempenhadas pelos cooperados, considerando o indivíduo e seu subgrupo, seus objetivos, nos quais estão inseridos, sua relação com a comunidade, os artefatos e as condições utilizados no trabalho cotidiano e, ainda, as relações internas de poder.

Quando analisadas as atividades dos cooperados individualmente, identificou-se o trabalho na cooperativa como forma de alcançar objetivos pessoais e de renda, como o sustento das famílias, um meio para desenvolver uma atividade produtiva que lhes propicie autonomia.

Percebe-se a atividade de cooperado como objeto, sendo que para Engeström (1987) atividade não está só relacionada a processos ou ações, mas a ações que levam a transformações, ações que transformam o objeto.

A atitude e a motivação dos cooperados a interagirem em um projeto de cooperação demonstram o que Engeström considera como um movimento de transformação, sendo que o motivo, para esses cooperados, é a necessidade de manter o sustento da família.
Encontramos também o que Engeström (1987) defende como sendo a noção de que a atividade individual deve ser substituída pela noção de atividade "de um indivíduo", uma vez que apenas as ações são individuais. A cooperação por conceito pressupõe trabalho compartilhado, que é encontrado em todos os momentos no exercício da atividade desenvolvida por essa comunidade.

Tal compartilhamento de ações e decisões ajuda a construir o ideal de cooperação e corrobora com o que Engeström (1999) argumenta: "as ações são reformuladas e revisadas à medida que as pessoas agem e, [...] propicia a construção e a redefinição do objeto que está relacionado ao potencial criativo da atividade".

A comunidade, como o grupo de cooperados, que compartilha os mesmos objetos gerais é encontrada no estatuto da cooperativa, em seu artigo 3ํㅡ, parágrafo V: "Reafirmar e aplicar a cooperação e a ajuda mútua como o princípio norteador do trabalho comum, que possibilite a organização da empresa sem a hierarquização das relações societárias".

Observou-se, da mesma forma, que artefatos, ferramentas ou signos mediando a atividade estão direcionando esforços na busca dos resultados almejados. Para Vygotsky (1978), as ferramentas são o condutor da influência humana sobre o objeto da atividade e é por meio dela que se leva à mudança nos objetos. Esse autor ainda argumenta que o uso de ferramentas é uma forma de acúmulo e transmissão do conhecimento social e de influência no comportamento dos indivíduos, visto que essas ferramentas são "construídas" pelo contexto cultural e social em que está ocorrendo seu uso.

0 uso de artefatos, ferramentas ou signos e a transmissão do conhecimento social e de influência no comportamento dos indivíduos possibilita a articulação de uma rede de relacionamento da cooperativa, tornando possível alterar o objeto da cooperativa de produtos agrícolas para artefatos de costura sem a dissolução da equipe de trabalho e a manutenção de seus membros.

Desta forma, como a atividade cooperativada é orientada por um objetivo que se reflete em possibilitar o trabalho e a renda dos indivíduos envolvidos na atividade e sendo que suas ações são realizadas por meio de ações coletivas e individuais, estabelece-se uma cadeia ou redes de ações que estão relacionadas umas com as outras por buscarem atingir 
a mesma meta, possibilitando que essa rede permeie ambientes fora da cooperativa.

0 estabelecimento dessas redes fica claro na atividade da cooperativa, quando em momentos de excesso de trabalho, procuram-se na comunidade pessoas que estejam aptas a executar a tarefa, colaborando assim com a entrega dos pedidos no tempo combinado. Essa rede deve ser constituída de pessoas aptas a realizarem o trabalho, tanto do ponto de vista de habilidades técnicas, como comprometidas com o resultado da cooperativa.

A divisão de trabalho se refere à divisão horizontal de tarefas entre os membros da cooperativa e ainda na divisão vertical de poder entre os cooperados. 0 trabalho na cooperativa é dividido entre todos os cooperados sendo que cada equipe é responsável por cada etapa. Isso não significa que haja discriminação entre as tarefas, já que todos os cooperados estão aptos a realizarem todas as tarefas no que se refere à manufatura. No entanto, existem momentos em que todos se revezam na atividade.

À luz da teoria, a divisão do trabalho é uma das tarefas mais difíceis de ser gerida. As diferentes posições dos participantes são uma fonte de dificuldade e de inovação, considerando que os participantes carregam suas próprias histórias e o próprio sistema de atividade exige ações de tradução desses significados e a negociação desses interesses. Essas dificuldades são ilustradas neste estudo por momentos de ruptura com o tipo de produto que era comercializado pela cooperativa e a mudança de gestão em momentos de crise, entre outros.

As normas explícitas são norteadas pelo estatuto da cooperativa, bem como em seu regimento interno. As normas e as regras implícitas estão condicionadas nas inter-relações entre as pessoas e nas relações de confiança que se estabelecem entre a equipe. Essas relações ficam claras na fala dos cooperados e são ilustradas pela mudança da liderança na gestão da cooperativa e na preocupação das dirigentes em manter um fundo de caixa para a manutenção dos salários dos trabalhadores em momentos de baixa na produção.

Assim, conforme a análise apresentada, a cooperativa estudada apresenta os elementos teóricos de um sistema de atividade, no qual o objeto da atividade é a manutenção da cooperativa, seus princípios norteadores e o alcance de seus objetivos por meio de suas ações individuais e coletivas. Os sujeitos do sistema de atividade são os cooperados, seus familiares e demais membros que direta ou indiretamente se beneficiam do trabalho e dele dependem em uma relação de interdependência com a cooperativa. As ferramentas são identificadas como os esforços para alcançar os objetivos propostos, a divisão do trabalho possibilita que o objeto seja alcançado e as regras garantem a manutenção das atividades da cooperativa, uma vez que define sua forma de atuação e o alinhamento com as ações dos cooperados frente aos objetivos da cooperativa.

0 gráfico abaixo ilustra o sistema de atividade da cooperativa estudada.

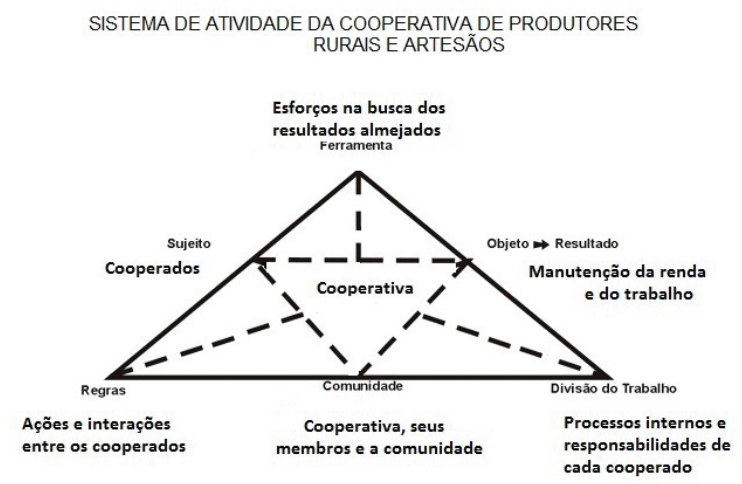

Figura 2 - Sistema de atividade da cooperativa de produtores rurais e artesãos. Fonte: a autora, adaptado de Engeström (1997).

$\mathrm{Na}$ categoria de análise Processo de Aprendizagem, buscou-se identificar o ciclo expansivo de aprendizagem, sendo que para Engeström (1987), o processo de aprendizagem é denominado pelo ciclo expansivo de aprendizagem, sendo que, por meio de questionamentos pelos indivíduos acerca de práticas socialmente aceitas, elas são repensadas, ressignificadas e recriadas.

Neste estudo, o ciclo de aprendizagem se caracteriza por sete etapas distintas como: questionar uma prática já utilizada pela cooperativa, analisar a possibilidade de implantação de uma nova prática, modelar uma solução possível, implementar o novo modelo, examinar a nova prática implantada refletindo sobre o processo consolidando uma nova prática, dando início a um novo ciclo de aprendizagem expansiva.

Buscamos identificar neste estudo como os cooperados aprendem e os motivos que impulsionam sua aprendizagem (questionamentos), e quais as novas formas de aprendizagem a partir de práticas inicialmente propostas. Essa análise foi realizada a

Psicol. Argum. 2014 jul./set., 32(78), 27-38 
partir da reconstrução da atividade de cooperado. 0 primeiro elemento a ser analisado é: como os cooperados aprendem e quais são as ações-chave do processo de aprendizagem.

A aprendizagem dessa comunidade passa a ser objeto de estudo a partir das necessidades percebidas por seus membros de estabelecer mudanças em seus padrões de comportamento acerca da sua condição de trabalho e geração de renda. 0 desalento a respeito de suas condições de vida e a iniciativa da prefeitura local em proporcionar cursos de cooperativismo promoveram em seus primeiros associados a percepção de que a partir do projeto haveria condições de melhoria, visto que a proposta pregava o trabalho comunitário e a associação dos trabalhadores em torno de um objetivo comum.

Percebe-se, então, a motivação dos primeiros cooperados pela formação da cooperativa e, consequentemente, a aprendizagem dos princípios do cooperativismo e do associativismo se deram a partir da necessidade individual de mudança. Percebeu-se que a mudança advém da consciência de que algo precisa ser feito em prol de uma melhoria de vida. Quando a conscientização ultrapassa a fase de internalização e passa a ser externalizada, a atividade em que as pessoas estão envolvidas também muda, porque a estrutura é transformada a partir de uma necessidade percebida, sendo que do ponto de vista formal, possibilitou o desenvolvimento do trabalho na cooperativa, com a superação das dificuldades que esse modelo de negócio impõe, devido a suas condições e fragilidade.

Outro ponto de análise está ancorado em por que os indivíduos aprendem, bem como os motivos que impulsionam sua aprendizagem, na qual percebemos que eles aprendem em suas relações sociais e por meio de suas práticas na comunidade onde estão socialmente inseridos. Para Engeström (1999), um sistema de atividade muda continuamente, transformando os instrumentos, os sujeitos e mesmo os objetos e inovando técnicas. Essa mutação contínua permite que os sistemas de atividade interajam e se sobreponham com outros sistemas de atividade, explicando, assim, como os indivíduos são capazes de transformar seus padrões de produção e trabalho inovando e criando nossas formas de aprender. Essa mudança contínua aparece por diversas vezes no relato dos cooperados e demonstra o movimento pela busca de novas possibilidades, sendo que muitos processos de aprendizagem na cooperativa surge em momentos de crise e são motivados pela necessidade de buscar novas oportunidades.

Ao longo da história da cooperativa, muitos cooperados desistiram do projeto, porém, na visão dos que permanecem no projeto, sua desistência sempre foi motivada pela falta de assimilação dos ideais de cooperativismo e do associativismo. Percebeu-se que quando as pessoas compartilham os mesmos ideais são capazes de se automotivar para a aprendizagem. Destaca-se que o sistema de atividade é sempre uma conjunção de múltiplos pontos de vista, tradições e interesses.

Quando deparamos com as possibilidades de novas formas de aprendizagem ressignificadas a partir de práticas inicialmente propostas, encontramos o princípio de contradições como fontes de mudança e de desenvolvimento. As contradições são os elementos que promovem os principais esforços de inovação e soluções adaptativas que provocam mudança e desenvolvimento no sistema de atividade. Essas tensões são relatadas em diversos momentos ao longo deste estudo. Esses momentos foram determinantes para a continuidade do trabalho da cooperativa, bem como resultaram em mudanças estratégicas no produto e na forma de organização da cooperativa. Essas contradições são agentes de aprendizagem e, segundo a teoria estudada, são determinantes para a expansão da aprendizagem.

Nessa perspectiva, a aprendizagem é motivada pelos diferentes contextos sociais e históricos dos indivíduos e ocorre em pequenos ciclos em espiral que se expandem gerando transformações no objeto. Essa expansão passa a ser o motivo da atividade, sendo que isso significa que questões como qual é o objetivo de uma atividade, o que é produzido e por que, são formuladas e reformuladas, frequentemente levando à formação de novas relações entre o motivo e a atividade (Engeström, 1995). A figura abaixo ilustra o ciclo expansivo da atividade desenvolvida pela cooperativa estudada.

De acordo com relatos dos cooperados, no momento em que se decidiu pela mudança na atividade principal da cooperativa de artesanatos em geral para a produção de bolsas, percebeu-se a necessidade de especialização no processo produtivo. Assim, a atividade, que antes era realizada de forma não padronizada, passou para um nível de especialização e profissionalização que não existia, sendo necessário um grande empenho e articulação de 


\section{CICLO EXPANSIVO DE APRENDIZAGEM DA ATIVIDADE DE PRODUÇÃO DE BOLSAS EM MATERIAIS RECICLÁVEIS}

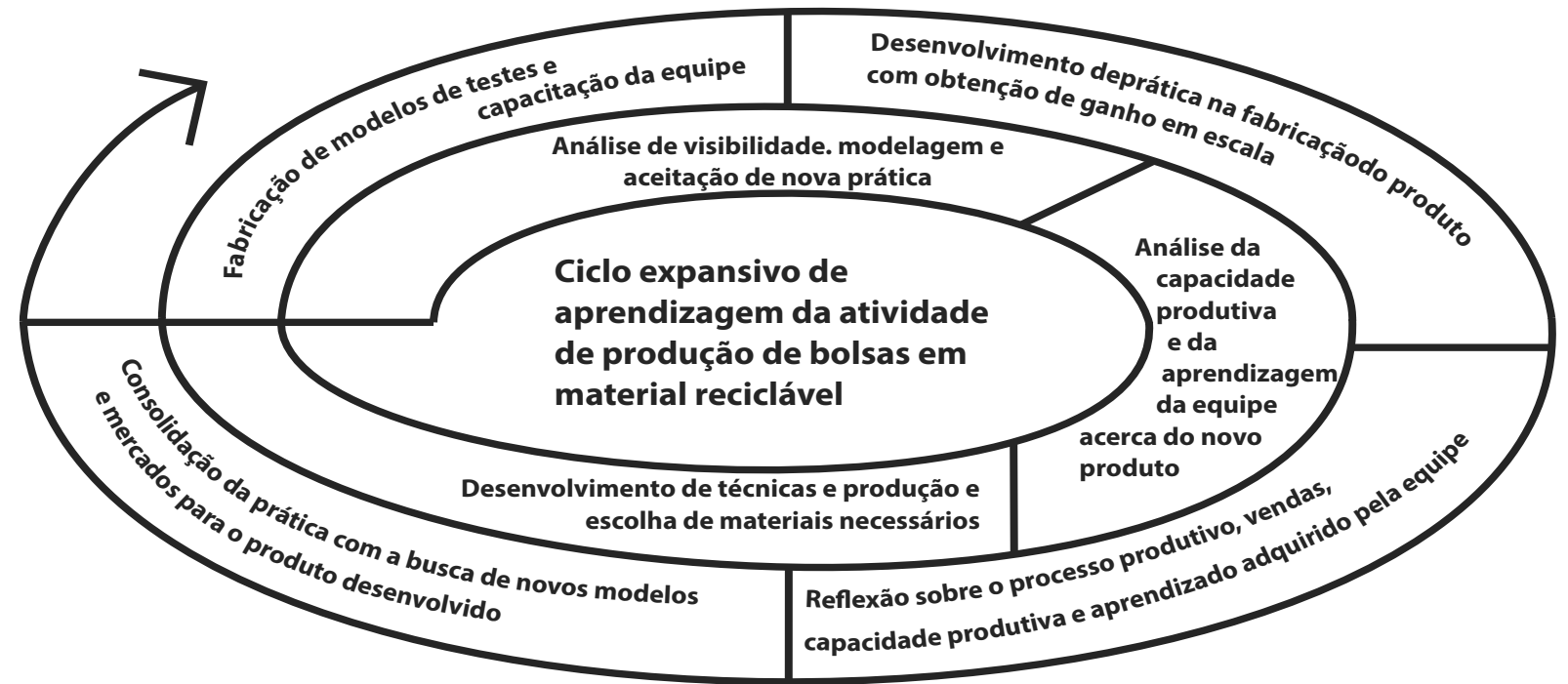

Figura 3 - Ciclo Expansivo da implantacãa da atividade de produção de bolsas e materiais recicláveis. Fonte: Ciclo de aprendizagem expansivo, adaptado de Engeström (1999).

todos os cooperados na aprendizagem da nova atividade, que se deu de maneira predominantemente informal.

A atividade de costura, principalmente, dependeu de uma aprendizagem especializada que somente ocorre a partir da interação entre os cooperados, e essa interação acontece cada vez que ocorre a entrada de um novo cooperado ou quando se decide pela produção de um novo modelo. Por ocasião da implantação da atividade das bolsas de materiais recicláveis encontramos várias contradições. As contradições primárias estão explícitas nas angústias no plano individual. A contradição interna surge a partir da insatisfação dos cooperados com a atividade realizada pela cooperativa e pela dificuldade de se obter seu objetivo de possibilitar trabalho e renda a seus associados e, também, pelo conflito entre as atividades individuais e o sistema de atividade. Essa angústia é recorrente na fala dos cooperados. As contradições secundárias ocorrem entre os diferentes elementos que constituem a atividade; aparecendo no estudo a partir de relatos dos cooperados sobre a dificuldade de gerenciar a cooperativa frente a um grande pedido e o conhecimento especializado necessário para atender às exigências do processo produtivo, com relação ao volume de produtos a entregar e o prazo. As contradições terciárias ocorrem entre o objeto/ motivo da atividade central e o objeto/motivo da inserção de outra atividade culturalmente mais avançada. Essa contradição foi relatada nos momentos em que a atividade central (produção de bolsas) substitui a atividade anteriormente executada. As contradições quaternárias são aquelas que surgem entre a atividade central em interação com as demais atividades. Essas contradições são relatadas, quando os cooperados são questionados sobre a gestão da cooperativa e as tomadas de decisão.

Se considerarmos o processo produtivo como a atividade central da cooperativa e a gestão como uma atividade essencial à sobrevivência do negócio, encontramos relatos de dificuldade de gestão e das implicações dos problemas de relacionamento que são inerentes ao processo.

Percebe-se que a atividade central analisada é fruto do interesse de um grupo de pessoas, que se reúnem em busca de um objetivo comum. Essa necessidade de buscar objetivos individuais por meio de ações coletivas é constante na fala dos cooperados e ilustra o pressuposto teórico deste estudo. 0 sistema de atividade estudado demonstra que as ações do grupo de cooperados levaram a transformações tanto na motivação como no objeto, gerando pequenos ciclos de aprendizagem que por meio de um processo contínuo de resoluções de contradições levam a ciclos completos de aprendizagem expansiva.

Psicol. Argum. 2014 jul./set., 32(78), 27-38 
Esses pequenos ciclos de aprendizagem são ilustrados pelos momentos de dificuldade enfrentados pelos cooperados, seja do ponto de vista da organização social do grupo, seja da necessidade de buscar novas ferramentas para melhorar o processo de trabalho.

0 enfrentamento dessas dificuldades se dá pelo questionamento das práticas existentes e pela necessidade de dissolução de conflitos, uma vez que dela depende a continuidade da cooperativa. É importante ressaltar que uma cooperativa, por princípio, deve apresentar característica de cooperação, autogestão, viabilidade econômica e solidariedade, sendo que todos esses princípios foram encontrados no empreendimento estudado.

Destacam-se alguns momentos em que foi percebido, a partir da análise dos dados coletados, o processo de aprendizagem expansiva.

1. A partir da percepção dos membros da cooperativa acerca da dificuldade de manter a atividade da agricultura familiar e o cultivo do cogumelo do sol, em função do baixo retorno financeiro na comercialização dos produtos.

No momento em que os cooperados começam a questionar a prática socialmente aceita e passam a buscar novas alternativas para alcançar seus interesses comuns, percebe-se um enfrentamento por parte dos cooperados pela busca de novas alternativas, sendo que a instabilidade enfrentada nesse momento foi, segundo os cooperados, motivo de mudança.

2. O sentimento de exploração do trabalho por parte de um parceiro, contrariando os princípios cooperativistas de autonomia, de reciprocidade e de solidariedade.

Como reflexo de um sentimento comum de exploração da força do trabalho, compartilhados pelos membros da cooperativa acerca da atividade de fabricação de "roupas de boneca", confronta-se uma prática socialmente aceita, possibilitando a busca por novas possibilidades de trabalho remunerado no âmbito da cooperativa.

3. Definição pela atividade de fabricação de bolsas e mochilas de material reciclado.
A definição de uma nova atividade pelos cooperados exigiu, por parte de todos, o desenvolvimento de uma atividade profissional que até então era desconhecida para a maioria dos cooperados. A nova atividade possibilitou sua profissionalização, inclusive no âmbito da comunidade (fora da cooperativa), uma vez que alguns dos ex-cooperados continuam prestando serviços para a cooperativa, sempre que necessário.

4. Elaboração de projeto de captação de recursos por parte da diretoria da cooperativa.

A captação de recursos por parte da diretoria, com a elaboração de projetos que foram enviados a entidades financiadoras com a aprovação dos recursos, caracteriza a capacidade de aprendizagem de seus membros, visto que apenas para a elaboração do primeiro projeto a cooperativa obteve ajuda da incubadora.

Percebe-se também que o grupo de cooperados foi capaz de expandir a aprendizagem recebida pela incubadora, desenvolvendo a partir de demandas internas, novas habilidades, considerando os saberes e experiências pessoais de seus membros que, compartilhados entre eles, reforçam a identidade da cooperativa e atendendo a demandas específicas do empreendimento estudado.

Identificaram-se no grupo estudado fatores que são considerados facilitadores e também aqueles que se apresentam como limitadores do processo de aprendizagem para responder as questões norteadoras da Matriz de aprendizagem expansiva, proposta por Engeström (2001). Como elementos facilitadores, destacam-se a interação social que o ambiente da cooperativa propicia, uma vez que pela própria convergência de interesses todas as pessoas são ouvidas, e todas as decisões são tomadas em conjunto e em consonância da maioria. Igualmente, percebeu-se que os conflitos e tensões que se estabelecem nas relações, ao mesmo tempo, possibilitam a mudança. Também pôde-se perceber que os múltiplos atores, múltiplas perspectivas (multivozes) e a historicidade tanto da cooperativa como dos indivíduos formam fontes de contradições que geraram trocas de experiências compartilhadas em grupo.

Entre os elementos limitadores, a ausência de toda iniciativa que coloque em risco o negócio, principalmente em virtude de seus membros 
dependerem da distribuição de renda de sua atividade para o sustento de suas famílias, pois, segundo eles, quaisquer decisões que gerem dificuldades internas diminuem a oferta de trabalho e, consequentemente, a renda de seus cooperados.

Dessa forma, as mudanças ocorrem de forma muito lenta, o que prejudica o crescimento do negócio, visto que as empresas, de modo geral, independente de sua modalidade ou ramo de atuação, estão inseridas em um ambiente de risco.

Destaca-se também a dificuldade de disseminar os ideais de cooperação e associativismo, pois as pessoas, em geral, não estão habituadas a trabalhar sob estas perspectivas, fazendo que um grande número de pessoas, mesmo depois de atendidos todos os critérios de aceitação e entrada, não permaneça por não entender e não compactuar com as exigências do modelo cooperativista, utilizando a cooperativa para atingir objetivos pessoais, como ascensão profissional, oportunidade de inserir-se no mercado de trabalho ou mesmo para ganhar experiência e sair em busca de outras oportunidades de trabalho, agora com uma profissionalização, mesmo que mínima. Este turnover traz prejuízo para a cooperativa tanto do ponto de vista da organização, pois a manutenção de pessoas que não compartilham os interesses comuns da cooperativa dificulta a organização do trabalho e gera conflitos internos de difícil solução, quanto do ponto de vista da aprendizagem. Assim, o princípio da "motivação que gera aprendizagem" diminuindo a interação bem como suas implicações positivas para o objetivo coletivo.

\section{Considerações finais}

No decorrer deste estudo, entendemos que a Economia Solidária, por meio de suas políticas públicas aplicadas pela Secretaria Nacional de Economia Solidária, materializadas em projetos sociais acabam tendo limitações na promoção de mudanças efetivas na vida das pessoas, em sua organização social e em suas práticas. Da mesma forma, percebe-se que as Incubadoras Tecnológicas de Cooperativas Populares das Universidades Públicas e Privadas, embora abarquem o ideal de disseminar as práticas do cooperativismo e dos conhecimentos necessários ao desenvolvimento de empreendimentos solidários, tem dificuldades em ser mediadora da apropriação cultural efetiva dos cooperados.
Por outro lado, percebeu-se que a Teoria da Atividade nos ofereceu conceitos mediadores e sensibilizadores da percepção cultural de um sistema de atividade com suas possibilidades e impossibilidades de expansão da aprendizagem. Aprendizagem demanda a existência de requisitos essenciais que são os motivos (motivações) e as contradições, visto que são elementos mediadores do processo de aprendizagem e interferem no sujeito, no objeto e nas ferramentas. Percebemos também a existência do ciclo de aprendizagem expansivo, pois, partindo-se de um questionamento acerca da situação atual, o cooperado desenvolve e inicia a criação da nova prática. Esse questionamento (contradições) se deu principalmente em momentos de dificuldade, gerando mudanças importantes no escopo da cooperativa.

Porém, mesmo com mais de 10 anos de existência, o projeto enfrenta uma série de dificuldades que colaboram para que haja um número grande de cooperados que não se identificam com os ideais cooperativistas e da economia solidária em que a busca por melhores condições de renda se sobrepõe a esses ideais, forçando-as a procurarem outras fontes de renda, nas quais o trabalho cooperativo não é capaz de retê-las.

Nesse contexto, observou-se que, embora os indivíduos pertencentes à comunidade pesquisada consigam expandir os ensinamentos (aprendizagem) recebidos pela incubadora, adaptando esses ensinamentos a suas realidades e desenvolvendo novas práticas, ela não é suficiente para promover a independência do projeto frente às dificuldades encontradas em uma economia de mercado. Percebese também uma relação de dependência não superada junto a órgãos financiadores e que o projeto não consegue inserir seus produtos em outras esferas do mercado e que lhes garantiria uma demanda mínima de bolsas e mochilas mensalmente. Em outras palavras, foi considerado que, do ponto de vista do indivíduo, a ação é emancipatória, pois qualifica-o para o trabalho. No entanto, o fato de a cooperativa apresentar-se como uma rede fechada impossibilita que ações conjuntas com outras cooperativas de produtos correlatos sejam alcançadas, o que em uma análise preliminar possibilitaria acesso a outros mercados.

Outro ponto a se considerar é o fato de a cooperativa não conseguir captar cooperados com visão de mercado, dispostos a atuarem não somente na

Psicol. Argum. 2014 jul./set., 32(78), 27-38 
manufatura, mas também como negociador. Essas pessoas poderiam atuar na busca de novos clientes da cooperativa e da própria rede, minimizando a dependência dos agentes financiadores e perdendo, mesmo que gradativamente, o laço assistencialista estabelecido. Essa é uma necessidade percebida pelos membros da cooperativa que demonstram em suas falas a necessidade premente de se inserirem de fato na economia de mercado. 0 questionamento da atual prática demonstra o próximo looping de aprendizagem expansivo.

Fica ainda a análise crítica da atuação da incubadora, visto que, como formadora dessas cooperativas e associações, deve ter como objetivo imputar nos indivíduos integrantes do projeto a busca pela autonomia e o afastamento natural das políticas de assistencialismo.

\section{Referências}

Andion, Carolina (2005). Gestão em Organizações da Economia Solidária: contornos de uma problemática. In Revista de administração Pública, FGV: vol 32(1): 7-25.

Brasil (2006). Ministério do Trabalho e do Emprego. Atlas da Economia Solidária no Brasil. SENAES. Recuperado de http:// www.fbes.org.br

Brasil (2005). Ministério de Ciência e Tecnologia. Rede de Tecnologia Social RTS. Recuperado de http:// www.brasil.gov.br/sobre/ciencia-e-tecnologia/ tecnologia-social/rts

Engeström, Yrjö (1999). Activity Theory and individual and social transformation. In: Perspectives on activity theory. Cambridge University Press, 19-38.

Engeström, Yrjö (1999). New forms of work and learning. University of Helsinki, Centre for Activity Theory and Developmental Work Research. Recuperado em 30 de abril de 2010, de http//www.edu.helsinki.fi/activity/4a.htm
Engeström, Yrjö (2001). Learning by expanding: an activity-theoretical approach to developmental research. Recuperado em 16 de janeiro de 2010, de http:// lchc.ucsd.edu/MCA/Paper/Engeström/expanding/ ch2.htm

Engeström, Yrjö (2001). Expansive learning at work: toward an activity theoretical reconceptualization. Journal of Education and Work, 14 (1).

França Filho, G. C. (2002). Terceiro Setor, Economia Social, Economia Solidária e Economia Popular: traçando fronteiras conceituais. Bahia Análise \& Dados, Salvador, 12 (1), 9-19.

Leontiev, A. N. (1974). The problem of activity in psychology. Soviet Psychology, 13 (2), 4-33.

Leontiev, A. N. (1978/1981). Actividad, conciencia y personalidad. Buenos Aires: Ediciones Ciencias del Hombre.

Neamtan, N. (2002). The social and Solidarity Economy: Toward Alternative Globalisation. In Symposium citizenship and globalization. Vancouver: Langara College.

Programa das Nações Unidas para o Desenvolvimento Recuperado de http://www.pnud.org.br

Programa Gestão Pública e Cidadania FGV-SP Recuperado de http://inovando.fgvsp.br

Singer, Paul (2002). Introdução à economia solidária. São Paulo: Fundação Perseu Abramo.

Singer, Paul (2003). Economia Solidária: um modo de produção e distribuição. In: A Economia Solidária no Brasil: A Autogestão como Resposta ao Desemprego. São Paulo: Contexto, 11-28.

Vygotsky, L. S. (1934/1978). Mind in society: The development of higher psychological processes. Cambridge, MA: Harvard University Press. 